\title{
Personalized Medicine and
} Tobacco-Related Health Disparities: Is There a Role for Genetics?

\author{
Chris Carlsten, $M D, M P H^{1}$ \\ Abigail Halperin, $M D, M P H^{2}$ \\ Julia Crouch, $M P H^{2}$ \\ Wylie Burke, MD, PbD \\ ${ }^{1}$ University of British Columbia, \\ Vancouver, Canada \\ ${ }^{2}$ University of Washington, Seattle, \\ Washington
}

\begin{abstract}
Genetic testing has been proposed as a means to increase smoking cessation rates and thus reduce smoking prevalence. To understand how that might be practically possible, with appreciation of the current social context of tobacco use and dependence, we performed a contextual analysis of smoking-related genetics and smoking cessation. To provide added value, genetics would need to inform and improve existing interventions for smokers (including behavioral and pharmacological treatments). Pharmacogenetics offers the most promising potential, because it may improve the efficacy of medication-based smoking cessations strategies. All proven interventions for treating tobacco dependence, however, including simple cost-effective measures, such as quit lines and physician counseling, are underutilized. As tobacco use occurs disproportionately among disadvantaged populations, efforts to improve smokers' access to health care, and to the tools that are known to help them quit, represent the most promising approaches for reducing smoking prevalence within these groups. Similar considerations apply to other chronic diseases contributing to population-level health disparities. We conclude that although genetics offers increasing opportunities to tailor drug treatment, and may in some cases provide useful risk prediction, other methods of personalizing care are likely to yield greater benefit to populations experiencing health disparities related to tobacco use.
\end{abstract}

Ann Fam Med 2011;9:366-371. doi:10.1370/afm.1244.

\section{THE CONTEXT OF THE PROBLEM}

$\mathrm{N}$ ot so long ago, physicians were featured in cigarette advertisements and could be seen smoking in the hallways of hospitals. The jarring quality of these images today is testimony to the enormously successful public health campaigns that have for decades delivered a clear message about the dangers of tobacco use and the questionable tactics of the industry that promotes it. ${ }^{1,2}$ Smoking bans, cigarette tax increases, countermarketing campaigns, and other broad efforts to reduce smoking have been remarkably effective; smoking prevalence in the United States has been reduced by more than one-half in the last 4 decades. ${ }^{3-6}$ Even so, US tobacco use rates have plateaued in recent years, and smoking continues to be the leading cause of morbidity and mortality. ${ }^{7}$ Globally tobacco use is rising sharply, and by 2030 it is expected to become the top preventable cause of death worldwide, with more than three-quarters of tobacco-related morbidity and premature mortality occurring in low- and middle-income countries. ${ }^{4}$ Broad-based public health initiatives ${ }^{8}$ are more effective than other measures at reducing smoking prevalence. ${ }^{9}$ Additionally, telephone quit lines and other programs that provide self-help resources, counseling, and pharmacotherapies at the 
individual level can increase quit rates substantially., Such tools remain more cost-effective than almost all other known clinical interventions, ${ }^{10,11}$ yet even among smokers motivated to quit, many do not utilize these proven methods. ${ }^{12}$ A particular concern is that smoking has become increasingly concentrated among the socially disadvantaged, including minorities, those with limited education or financial resources, and other such vulnerable groups as the homeless and mentally ill. ${ }^{6}$

Genetic approaches have been proposed as a means to improve effectiveness of smoking cessation interventions. There are 2 approaches suggested in support of this proposition: first, that information about risk for smoking-related disease will increase the individual smoker's motivation to quit and remain nonsmoking, ${ }_{1}^{13}$ and second, that information about genetic susceptibility to nicotine addiction can be used to increase the effectiveness of pharmacotherapy. ${ }^{14}$ In the context of these hypotheses, a number of recent studies document associations between gene variants and various measures of smoking behavior ${ }^{15}$ and nicotine metabolism. ${ }^{16}$ The enthusiasm for this approach is in keeping with widely held expectations that genetic risk information will usher in a new era of personalized medicine, in which health care is individualized on the basis of genetic susceptibility. ${ }^{13,17-21}$ This paradigm necessitates a realistic assessment of potential benefit for using genetic information in individual clinical care, both in general ${ }^{22}$ and as it applies specifically to health conditions, such as tobacco dependence, where major disparities exist

Our thesis is that to provide value, genetics must inform and improve existing interventions for smokers, as well as enhance smokers' access to high-quality health care, particularly for those who are disadvantaged. We argue that existing community- and individual-based tools known to reduce smoking prevalence, which are tailored to the social circumstances of these vulnerable groups, represent a more promising approach than genetics for decreasing smoking-related health disparities.

\section{EVIDENCE THAT GENETIC KNOWLEDGE INCREASES SMOKING CESSATION}

Empiric data so far provide little or no evidence that knowledge of genetic variants yields long-term benefit in terms of quit rates. ${ }^{23}$ For example, a study that incorporated genetic testing for lung cancer susceptibility (genotyping for the glutathione S-transferase M1 gene) in a smoking cessation program found that genetic feedback - regardless of test result_-enhanced cessation rates at 6 months, but the effect did not persist at 12 months. ${ }^{24}$ Another study examining the impact of genetic testing for alpha-1 antitrypsin on smokers' behavior similarly noted increased attempts to quit but no effect on sustained abstinence. ${ }^{25}$ A study of knowledge about L-myc polymorphisms to motivate smoking cessation showed no effect. ${ }^{26}$ In contrast, a recent study showed that simply informing a patient of his or her lung age, a low-cost technique requiring only a spirometer, more than doubled the 12 -month quitting rate compared with conventional treatment. ${ }^{27}$

Pharmacogenetics - the use of genetic testing to help identify the regimen most likely to benefit a smoker with a particular genotype-appears more promising. ${ }^{28}$ Current research offers interesting findings relevant for both specialized and general clinical settings. For example, the nicotinic agonist DMXBA appears to influence auditory gating, and genetic variation may be important for the gating deficits that are associated with schizophrenia ${ }^{29}{ }_{i}$ in addition, associations have been reported between genetic variation in nicotinic receptors and schizophrenia. ${ }^{30}$ These intriguing findings suggest that a better understanding of interactions between gene variants associated with smoking behavior and schizophrenia could lead to beneficial pharmacologic treatments for schizophrenic patients who are smokers and possibly confer broader benefits as well.

Recent research has also documented associations between variants in the CYP26A gene and both nicotine metabolism and smoking behavior. ${ }^{14,16,31,32}$ Potential clinical applications of this knowledge are suggested in a recent article by Lerman and colleagues ${ }^{33}$ showing that extended transdermal nicotine therapy achieved higher quit rates than standard therapy in smokers with CYP2D6 variants resulting in poor nicotine metabolism, but not in smokers with normal metabolism. These data point to a potential role for pharmacogenetic testing in identifying a subset of patients who may benefit from intensive pharmacotherapy for smoking cessation. Modeling exercises, however, suggest that genetic tailoring of smoking cessation pharmacotherapy may not be cost-effective, ${ }^{34}$ even with favorable assumptions (eg, a single-gene test for a somewhat common allele with a substantial relative risk). ${ }^{35,36}$

\section{PERSONALIZED MEDICINE}

The pharmacogenetic approach to smoking cessation is in keeping with the concept of personalized medicine as it is commonly defined-the use of genetic testing to help ensure "the right medicine for the right patient at the right time." ${ }^{37}$ But a broader concept of personalized medicine is increasingly being recognized. Feero et al, for example, note,

....although personalized medicine has many definitions, most share the core idea that any one patient's health is best managed by tailoring preventive measures 
and treatment to personal preferences as well as to the patient's particular environmental and biologic_-including genomic-attributes. ${ }^{38}$

This more expansive definition is consistent with a body of empiric studies, normative analysis, and commentary that defines the best medical care as addressing a broad range of patient concerns, valuing and respecting the patient's identity as a whole person. ${ }^{39-42}$ As primary care clinicians have long recognized, physicians must be attentive to the patient's personal values and life circumstances if they want to provide the best care ${ }^{43}$; optimally, the patient and physician develop a working alliance to choose medical care that best addresses the patient's health needs. ${ }^{44}$ In this context, genetic information is an evolving tool that may sometimes assist clinical decision making. Like any tool, however, its value will vary with the clinical context; as a tool, it will always be secondary to the therapeutic relationship in which the health care clinician, with an understanding of the patient's medical and life circumstances, along with the associated moral authority, ${ }^{45}$ may make the care personal and potentially more effective. ${ }^{43}$

With smoking, the ultimate goal is always the same: helping smokers quit and remain nonsmokers to prevent further risk of tobacco-related disease and premature death. A wealth of clinical research ${ }^{8}$ already shows that assessment of a patient's tobacco use history and experience with prior quit attempts, in the context of other comorbidities and social factors, informs which medical and behavioral treatments are most likely to help that individual quit permanently ${ }^{46}$ — in short, a personalized approach based on knowing the smoker and his or her circumstances. Because most smokers experience difficult social and personal circumstances, it is these circumstances, rather than genetic susceptibilities, that represent the fundamental challenge and opportunity for clinicians to help affect positive behavior change in their patients who smoke.

\section{WHO SMOKES? DISPARITIES IN TOBACCO USE}

Data on socioeconomic disparities in tobacco use are striking. Although the overall prevalence of smoking in the United States is $20 \%, 44 \%$ of people with only a high school or equivalent degree are smokers, contrasted with $11 \%$ of college graduates, $6 \%$ with graduate degrees, and $2 \%$ of physicians. ${ }^{6,47}$ Additionally, it is estimated that more than $40 \%$ of cigarettes smoked in the United States are consumed by those currently suffering from major psychiatric illnesses. ${ }^{48}$

These disparities extend to quitting rates. Smokers in the United States with less education and lower socioeconomic status (SES) are just as likely to try quitting - $40 \%$ to $50 \%$ of smokers regardless of SES made an attempt in 2000_-but they are substantially less likely to succeed. ${ }^{49,50}$ Important reasons for this disparity include differences in the reach of community-based measures and in access to proven aids to quitting, such as counseling and medications, ${ }^{51}$ as well as certain market forces and community norms that undermine efforts which might otherwise be effective in this population. For example, illegal street sales of less-expensive, untaxed tobacco products rose in lowincome neighborhoods in New York City after excise tax increases, and low-SES smokers have been found to be less responsive to media campaigns promoting smoking cessation than smokers of higher SES. ${ }^{49,52}$

The groups experiencing higher smoking prevalence are disproportionately minorities ${ }^{47}$ and populations with a greater burden of common and disabling chronic diseases, such as chronic obstructive pulmonary disease, asthma, diabetes, heart disease, and depression; they also have less access to high-quality health care. ${ }^{53}$ Thus, the first step in helping these smokers quit is to ensure access to evidence-based cessation methods, including counseling and medication (with support for adequate dosage and proper usage) based on reported history and symptoms. ${ }^{46}$ This validated approach, ${ }^{54}$ which includes tailoring treatment to smoking history, deserves the highest public health priority, especially because the effectiveness of approved pharmacotherapies is the same for minority low-income smokers as it is for white smokers. ${ }^{55}$ Further, even a modestly priced genetic test-eg, in the range of $\$ 100$ to $\$ 300$ - along with the associated therapy, would likely be beyond the reach of most smokers. Public health care funders are unlikely to consider expenditures for genetic testing prudent without proof of considerable added benefit or a rigorous trial of lower cost alternatives. Instead, as with other medical technology, ensuring full access to established therapies offers the biggest potential gain. ${ }^{56}$

Beyond access to proven smoking cessation techniques, efforts are needed to tailor behavioral counseling to the social and cultural circumstances of the smoker. The balance of benefit and risk may be distinct for disadvantaged smokers as a result of higher social stress and comorbid conditions. In addition, remaining smoke-free after quitting may be difficult because of the larger proportion of smokers in their family and wider social environment. More fundamentally, helping disadvantaged smokers requires efforts beyond tailoring smoking cessation programs. Motivation and thus ability to quit smoking may be undermined by a lay epidemiology that recognizes the limited health and life opportunities for many people living in deprived 
circumstances. ${ }^{57}$ From this perspective, programs to help disadvantaged smokers quit are more likely to be successful when linked with broader efforts to improve their life circumstances.

Dedicated research partnerships and capacity building will be needed to develop and implement appropriate outreach and tailor the use of proven cessation aids within different underserved communities. ${ }^{58}$ Obstacles for the poor may be distinct from those for the mentally ill, and understanding gained from sociologic research is likely to be required to adapt the messages and methods used in mainstream smoking cessation efforts to benefit people from various marginalized groups. ${ }^{52,59}$ For the groups that bear the highest burden of smoking-related harm in our society, it will be difficult to demonstrate a role for genetics until we have fully implemented what we already know and identified ways in which existing strategies can be productively brought to marginalized or disadvantaged smokers and their communities, ${ }^{60}$ ideally in ways that promote better access to health care in general. ${ }^{57}$

In conclusion, the incidence and outcomes of smoking are strongly influenced by environmental and social conditions, including lack of access to simple, proven methods of smoking cessation for many smokers. Tailoring these methods to socially disadvantaged environments should be a priority for efforts focused on helping individual tobacco users quit. Nevertheless, it would be foolhardy to dismiss any potential added value of genetics. Broadly speaking, the most likely scenario under which genetics could provide incremental benefit for reducing harms from smoking is in gene-by-environment applications that elucidate the role of particular exposures and thereby support interventions to reduce these exposures. For individual treatment of tobacco dependence, the most beneficial application of genetics will likely be within pharmacogenetics. In keeping with current evidence standards for therapeutic interventions, however, genetic tests that are proposed to enhance treatment of such health conditions must be assessed against current proven therapies. Additionally, in addressing disparities, all genetic approaches should be tested in the social environments and health systems available to the disadvantaged populations suffering disproportionate burdens from these health problems. ${ }^{27}$

Cost is a crucial part of the evaluation; even if genetic testing were found to add value, it is unlikely to benefit those who need help the most, thus risking an exacerbation of existing disparities. As suggested by others, ${ }^{61}$ evidence for cost-effectiveness is lacking for smoking-related genetic testing; this deficiency is particularly important in light of evidence that such policy strategies as taxation and mass media have been shown to be extremely cost-effective in reducing smoking prevalence and to concurrently reduce smoking-related health disparities. ${ }^{62}$

Genetic research offers extraordinary promise for advancing understanding of disease biology ${ }^{63,64}$ and stimulating innovative drug development. ${ }^{65}$ Some uses of genetic testing, including pharmacogenetics, provide unique clinical value. ${ }^{66-68}$ Reducing the prevalence of cigarette smoking, however, particularly among the disadvantaged populations who constitute the majority of smokers, is an unlikely context for such added value. Rather, studies of the genetic contributors to tobacco dependence are more likely to provide benefit as models for understanding gene-environment interactions or the biology of addiction.

The use of gene variants associated with smoking in the study of such larger questions, while promising, should not be confused with the public health imperative to reduce the enormous toll of tobacco use and addiction ${ }^{69}$; it is a particular disservice to suggest otherwise in the context of unregulated marketing of genetic testing services. Knowledge about the genetics of nicotine addiction and tobacco-related disease is an implausible tool for reducing disparities, even incrementally, compared with public policies directed toward safer environments, increased educational and employment opportunities, and better health care for disadvantaged people. An essential component of this effort is that treatment be personalized, based on attention to the social and economic inequities that remain at the heart of the tobacco epidemic and most of our society's growing health disparities. ${ }^{70}$

To read or post commentaries in response to this article, see it online at http:/lwww.annfammed.org/cgi/content/full/9/4/366.

Submitted June 7, 2010; submitted, revised, December 20; accepted January 25, 2011.

Key words: Smoking; genetics; personalized medicine; health status disparities

Funding support: This article was supported in part by the Center for Genomics and Healthcare Equality (NIH grant P50HG003374).

Acknowledgment: We thank Drs Peter Pare and Dirkje Postma for helpful discussions regarding the article.

\section{References}

1. Landman A, Glantz SA. Tobacco industry efforts to undermine policy-relevant research. Am J Public Health. 2009;99(1):45-58.

2. World Health Organization. Tobacco Industry Interference With Tobacco Control. Geneva: WHO; 2008.

3. Warner K. Tobacco policy research: insights and contributions to public health policy. In: Warner KE, Isaacs SL, Knickman JR, eds. Tobacco Control Policy. San Francisco, CA: Jossey-Bass; 2006:3-86. 
4. World Health Organization. WHO Report on the Global Tobacco Epidemic, 2008: The MPOWER Package. Geneva: WHO; 2008.

5. Schroeder SA. Shattuck Lecture. We can do better-improving the health of the American people. N Engl J Med. 2007;357(12): 1221-1228.

6. Zhu S, Melcer T, Sun J, Rosbrook B, Pierce JP. Smoking cessation with and without assistance: a population-based analysis. Am J Prev Med. 2000;18(4):305-311

7. Centers for Disease Control and Prevention (CDC). Cigarette smoking among adults and trends in smoking cessation-United States, 2008. MMWR Morb Mortal Wkly Rep. 2009;58(44):1227-1232.

8. Fiore $M$, Jaén CR, Baker TB, et al. Clinical Practice Guideline Treating Tobacco Use and Dependence 2008 Update Panel, Liaisons, and Staff. A clinical practice guideline for treating tobacco use and dependence: 2008 update. A US Public Health Service report. Am J Prev Med. 2008;35(2):158-176.

9. Warner KE, Mackay JL. Smoking cessation treatment in a publichealth context. Lancet. 2008;371(9629):1976-1978.

10. Curry SJ, Keller PA, Orleans CT, Fiore MC. The role of health care systems in increased tobacco cessation. Annu Rev Public Health 2008;29:411-428

11. Maciosek MV, Coffield AB, Edwards NM, Flottemesch TJ, Goodman MJ, Solberg LI. Priorities among effective clinical preventive services: results of a systematic review and analysis. Am J Prev Med. 2006;31(1):52-61.

12. Centers for Disease Control and Prevention (CDC), Office on Smok ing and Health. Reducing Tobacco Use: A Report of the Surgeon General. 2000. http://www.cdc.gov/tobacco/data_statistics/sgr/2000/ highlights/tobacco/index.htm. Accessed May 19, 2009.

13. Collins FS. Shattuck lecture-medical and societal consequences of the Human Genome Project. N Engl J Med. 1999;341(1):28-37.

14. Lerman C, Berrettini W. Elucidating the role of genetic factors in smoking behavior and nicotine dependence. Am J Med Genet B Neuropsychiatr Genet. 2003;118B(1):48-54.

15. Caporaso N, Gu F, Chatterjee N, et al. Genome-wide and candidate gene association study of cigarette smoking behaviors. PLOS ONE. 2009;4(2):e4653. doi:10.1371/journal.pone.0004653.

16. Mwenifumbo J, Tyndale RF. Molecular genetics of nicotine metabolism. Handb Exp Pharmacol. 2009;(192):235-259.

17. Zhou SF, Di YM, Chan E, et al. Clinical pharmacogenetics and potential application in personalized medicine. Curr Drug Metab. 2008;9(8):738-784.

18. Personalized Medicine Coalition. http://www.personalizedmedicinecoalition.org/about/about-personalized-medicine/personalizedmedicine-101. Accessed Dec 31, 2008.

19. Snyderman R. Personalized medicine means planning for your future health. Analyzing a patient's health risks and focusing on prevention and health planning are key components of the 21st century's new health care. Health News. 2008;14(11):6-7.

20. Gammon K. Leroy Hood: look to the genome to rebuild health care. Wired. Sep 22, 2008.

21. Guttmacher AE, Collins FS. Welcome to the genomic era. N Engl J Med. 2003;349(10):996-998.

22. O'Neill SC, McBride CM, Alford SH, Kaphingst KA. Preferences for genetic and behavioral health information: the impact of risk factors and disease attributions. Ann Behav Med. 2010;40(2):127-137.

23. Hall WD, Gartner CE, Carter A. The genetics of nicotine addiction liability: ethical and social policy implications. Addiction. 2008;103 (3):350-359.

24. McBride CM, Bepler G, Lipkus IM, et al. Incorporating genetic susceptibility feedback into a smoking cessation program for AfricanAmerican smokers with low income. Cancer Epidemiol Biomarkers Prev. 2002;11(6):521-528.
25. Carpenter MJ, Strange $C$, Jones $Y$, et al. Does genetic testing result in behavioral health change? Changes in smoking behavior following testing for alpha-1 antitrypsin deficiency. Ann Behav Med. 2007;33(1):22-28

26. Hishida A, Terazawa T, Mamiya T, et al. Efficacy of genotype notification to Japanese smokers on smoking cessation - an intervention study at workplace. Cancer Epidemiol. 2010;34(1):96-100.

27. Parkes G, Greenhalgh T, Griffin M, Dent R. Effect on smoking quit rate of telling patients their lung age: the Step2quit randomised controlled trial. BMJ. 2008;336(7644):598-600.

28. Uhl GR, Liu QR, Drgon T, et al. Molecular genetics of successful smoking cessation: convergent genome-wide association study results. Arch Gen Psychiatry. 2008;65(6):683-693.

29. Martin LF, Freedman R. Schizophrenia and the alpha7 nicotinic acetylcholine receptor. Int Rev Neurobiol. 2007;78:225-246.

30. Stephens SH, Logel J, Barton A, et al. Association of the 5\$-upstream regulatory region of the alpha7 nicotinic acetylcholine receptor subunit gene (CHRNA7) with schizophrenia. Schizophr Res. 2009;109 (1-3):102-112.

31. Nakajima M, Fukami T, Yamanaka H, et al. Comprehensive evaluation of variability in nicotine metabolism and CYP2A6 polymorphic alleles in four ethnic populations. Clin Pharmacol Ther. 2006;80(3): 282-297.

32. Al Koudsi N, Hoffmann EB, Assadzadeh A, Tyndale RF. Hepatic CYP2A6 levels and nicotine metabolism: impact of genetic, physiological, environmental, and epigenetic factors. Eur J Clin Pharmacol. 2010;66(3):239-251

33. Lerman C, Jepson C, Wileyto EP, et al. Genetic variation in nicotine metabolism predicts the efficacy of extended-duration transdermal nicotine therapy. Clin Pharmacol Ther. 2010;87(5):553-557.

34. Gordon LG, Hirst NG, Young RP, Brown PM. Within a smokingcessation program, what impact does genetic information on lung cancer need to have to demonstrate cost-effectiveness? Cost Eff Resour Alloc. 2010;8:18

35. Heitjan DF, Asch DA, Ray R, Rukstalis M, Patterson F, Lerman C. Cost-effectiveness of pharmacogenetic testing to tailor smokingcessation treatment. Pharmacogenomics J. 2008;8(6):391-399.

36. Welton NJ, Johnstone EC, David SP, Munafò MR. A cost-effectiveness analysis of genetic testing of the DRD2 Taq1A polymorphism to aid treatment choice for smoking cessation. Nicotine Tob Res. 2008;10(1):231-240

37. Hamburg MA, Collins FS. The path to personalized medicine. N Engl J Med. 2010;363(4):301-304.

38. Feero WG, Guttmacher AE, Collins FS. Genomic medicine-an updated primer. N Engl J Med. 2010;362(21):2001-2011

39. Stewart M, Brown JB, Donner A, et al. The impact of patient-centered care on outcomes. J Fam Pract. 2000;49(9):796-804

40. Gené-Badia J, Ascaso C, Escaramis-Babiano G, et al. Personalised care, access, quality and team coordination are the main dimensions of family medicine output. Fam Pract. 2007;24(1):41-47.

41. Stange KC. The generalist approach. Ann Fam Med. 2009;7(3): 198-203.

42. Safran DG. Defining the future of primary care: what can we learn from patients? Ann Intern Med. 2003;138(3):248-255.

43. Candib LM, Gelberg L. How will family physicians care for the patient in the context of family and community? Fam Med. 2001; 33(4):298-310.

44. Fuertes JN, Mislowack A, Bennett J, et al. The physician-patient working alliance. Patient Educ Couns. 2007;66(1):29-36.

45. Stange KC. Power to advocate for health. Ann Fam Med. 2010; 8(2):100-107.

46. Hughes J. An algorithm for choosing among smoking cessation treatments. J Subst Abuse Treat. 2008;34(4):426-432. 
47. Fagan P, Moolchan ET, Lawrence D, Fernander A, Ponder PK. Identifying health disparities across the tobacco continuum. Addiction. 2007;102(Suppl 2):5-29.

48. Lasser K. Smoking and mental illness: a population-based prevalence study. JAMA. 2000;(284):2606-2610.

49. Niederdeppe J, Fiore MC, Baker TB, Smith SS. Smoking-cessation media campaigns and their effectiveness among socioeconomically advantaged and disadvantaged populations. Am J Public Health. 2008;98(5):916-924.

50. Barbeau EM, Krieger N, Soobader MJ. Working class matters: socioeconomic disadvantage, race/ethnicity, gender, and smoking in NHIS 2000. Am J Public Health. 2004;94(2):269-278.

51. Fu SS, Kodl MM, Joseph AM, et al. Racial/Ethnic disparities in the use of nicotine replacement therapy and quit ratios in lifetime smokers ages 25 to 44 years. Cancer Epidemiol Biomarkers Prev. 2008;17(7):1640-1647.

52. Shelley D, Cantrell MJ, Moon-Howard J, Ramjohn DQ, VanDevanter $\mathrm{N}$. The $\$ 5$ man: the underground economic response to a large cigarette tax increase in New York City. Am J Public Health. 2007; 97(8):1483-1488.

53. Smedley BD, Stith AY, Nelson AR, eds. Unequal Treatment: Confronting Racial and Ethnic Disparities in Health Care. Washington DC: Institute of Medicine; 2003.

54. Sachs DP, Hodgkin JE, Bostrom AG. Improving treatment outcome in the face of increasingly severe nicotine dependence in patients seeking tobacco-dependence treatment. Chest. 2008;134(s53002).

55. Fu SS, Burgess DJ, Hatsukami DK, et al. Race and nicotine replacement treatment outcomes among low-income smokers. Am J Prev Med. 2008;35(6)(Suppl):S442-S448.

56. Woolf SH, Johnson RE. The break-even point: when medical advances are less important than improving the fidelity with which they are delivered. Ann Fam Med. 2005;3(6):545-552.

57. Lawlor DA, Frankel S, Shaw M, Ebrahim S, Smith GD. Smoking and ill health: does lay epidemiology explain the failure of smoking cessation programs among deprived populations? Am J Public Health. 2003;93(2):266-270.
58. Wisconsin Department of Health and Human Services. Wisconsin Tobacco Control Disparities Strategic Planning Workshop. Bringing Everyone Along: A Strategic Plan to Identify and Eliminate TobaccoRelated Disparities in Wisconsin. Wisconsin Department of Health and Human Services; 2002.

59. Niederdeppe J, Kuang X, Crock B, Skelton A. Media campaigns to promote smoking cessation among socioeconomically disadvantaged populations: what do we know, what do we need to learn, and what should we do now? Soc Sci Med. 2008;67(9):1343-1355.

60. Shortell SM, Swartzberg J. The physician as public health professional in the 21st century. JAMA. 2008;300(24):2916-2918.

61. Hall WD. A research agenda for assessing the potential contribution of genomic medicine to tobacco control. Tob Control. 2007;16(1): 53-58.

62. Siahpush M, Wakefield MA, Spittal MJ, Durkin SJ, Scollo MM. Taxation reduces social disparities in adult smoking prevalence. Am J Prev Med. 2009;36(4):285-291.

63. Ramsey SA, Gold ES, Aderem A. A systems biology approach to understanding atherosclerosis. EMBO Mol Med. 2010;2(3):79-89.

64. Korkola J, Gray JW. Breast cancer genomes-form and function. Curr Opin Genet Dev. 2010;20(1):4-14.

65. Gresham V, McLeod HL. Genomics: applications in mechanism elucidation. Adv Drug Deliv Rev. 2009;61(5):369-374.

66. Ma WW, Adjei AA. Novel agents on the horizon for cancer therapy. CA Cancer J Clin. 2009;59(2):111-137.

67. Ginsburg GS, Willard HF. Genomic and personalized medicine: foundations and applications. Transl Res. 2009;154(6):277-287.

68. Mallal S, Phillips E, Carosi G, et al; PREDICT-1 Study Team. HLAB*5701 screening for hypersensitivity to abacavir. N Engl J Med. 2008;358(6):568-579

69. Hall W, Madden P, Lynskey M. The genetics of tobacco use: methods, findings and policy implications. Tob Control. 2002;11(2):119-124.

70. Graham H. Why social disparities matter for tobacco-control policy. Am J Prev Med. 2009;37(2)(Suppl):S183-S184.

\section{CORRECTION}

Ann Fam Med 2011;371. doi:10.1370/afm.1294

Brinks A, van Rijn RM, Willemsen SP, et al. Corticosteroid injections for greater trochanteric pain syndrome: a randomized controlled trial in primary care. Ann Fam Med. 2011;9(3):226-234.

Under the Participants heading in the Methods section, the American College of Rheumatology criteria for osteoarthritis should include morning stiffness of up to 60 minutes, not longer than 60 minutes as mentioned in this study.

In Table 2. Primary and Secondary Outcome Measures at the 3- and 12-Month Follow-up. Under the column heading Secondary outcomes, Usual Care, 3 mo, a superscript 1 beside (22.7) in the 2 nd set of numbers across from WOMAC pain, Mean (SD), is in error and should be ignored. 